\title{
Análise da implementação da Política de Dados Abertos no âmbito do Poder Executivo Federal
}

\author{
Analysis of the implementation of the Open Data Policy in the Federal \\ Executive Government
}

\section{Análisis de la implementación de la Política de Datos Abiertos en el ámbito del Poder Ejecutivo Federal}

\author{
Janaina dos Santos Melo | janainaaa.melo@gmail.com \\ Universidade de Brasília, Centro de Apoio ao Desenvolvimento Tecnológico. Brasília, DF, Brasil. \\ Maria Fernanda Mascarenhas dos Santos Melis | mfernanda.melis@gmail.com \\ Universidade de Brasília, Centro de Apoio ao Desenvolvimento Tecnológico. Brasília, DF, Brasil.
}

\section{Resumo}

Os dados abertos governamentais podem resultar em benefícios para a sociedade que vão além da transparência dos atos públicos. Este trabalho tem por objetivo analisar o estágio de implementação da política de dados abertos em órgãos do Poder Executivo Federal, tendo como base os documentos normativos que regulam as ações organizacionais de abertura de dados: Decreto n. 8.777/2016, Manual para elaboração de PDA, Cartilha para Publicação de Dados Abertos no Brasil e Plano de Ação da INDA. A coleta de dados se deu entre os meses de fevereiro e abril de 2017, por meio de observações no Portal Brasileiro de Dados Abertos, no Wiki da INDA, nos websites oficiais dos órgãos, bem como por solicitações de informações complementares no e-SIC. Conclui-se que existem órgãos que não possuem PDA e mesmo assim possuem dados disponibilizados e há órgãos que possuem o PDA em desacordo com o manual de elaboração.

Palavras-chave: Dado governamental aberto; Poder Executivo Federal; Transparência; Controle social; Política de dados abertos.

\begin{abstract}
Open government data can result in benefits for society that go beyond the transparency of public acts. This paper aims to analyze the stage of implementation of the open data policies in Federal Executive Government, based on the normative documents that regulate the organizational actions of data disclosure: Decree n. 8.777/2016, Manual for PDA elaboration, Hornbook for elaboration of Brazil's Open Data and INDA's Plan of Action. The data collect occurred between February and April 2017, with observations on the Brazilian's Open Data Portal, the INDA Wiki, the official websites of the agencies, as well as requests for additional information in the e-SIC. It is concluded that there are organs that do not have PDA and yet have data available and there are organs that have the PDA in disagreement with the manual of elaboration.
\end{abstract}

Keywords: Open government data; Federal Executive Government; Transparency; Social control; Open Data Policy. 


\section{Resumen}

Los datos abiertos gubernamentales pueden resultar en beneficios para la sociedad que van más allá de la transparencia de los actos públicos. Este trabajo tiene por objetivo analizar la etapa de implementación de la política de datos abiertos en órganos del Poder Ejecutivo Federal, teniendo como base los documentos normativos que se dedican a las acciones organizativas de apertura de datos: Decreto n. 8.777/2016, Manual para la elaboración de PDA, Cartilla Técnica para la publicación de datos abiertos en Brasil y Plan de Acción de la Infraestructura Nacional de Datos Abiertos. La recolección de datos sucedió entre los meses de febrero y abril del año 2017, por medio de observaciones en la Portada Brasileña de Datos Abiertos, en el Wiki de la INDA, en los sitios online oficiales de los órganos, así como por solicitudes de informaciones complementarias por el e-SIC. Se concluye que existen órganos que no poseen PDA y aún así poseen datos disponibles y hay órganos poseen el PDA en desacuerdo con el manual de elaboración.

Palabras clave: Dato gubernamental abierto; Poder Ejecutivo Federal; Transparencia; Control Social; Política de Datos Abiertos.

\section{Proposta}

Com o avanço das tecnologias de informação e comunicação (TICs), as estruturas administrativas governamentais passaram a criar novas formas de se relacionar com a sociedade, que não por meio físico.

Para consolidar essas formas de relacionamento, criou-se o Grupo de Trabalho Interministerial, pelo Decreto Presidencial de 3 de abril de 2000, com a finalidade de examinar e propor políticas, diretrizes e normas relacionadas com as novas formas eletrônicas de interação, dando início ao Programa Governo Eletrônico (e-Gov). Desde então, o governo federal vem implementando projetos com ênfase em iniciativas voltadas para o uso das tecnologias de informação e comunicação (TIC) no exercício da cidadania, envolvendo a administração pública, a sociedade e o setor privado.

Em 2011, foi sancionada a Lei n. 12.527, também conhecida como Lei de Acesso à Informação Pública, que regulamenta o acesso a dados e informações detidas e produzidas pelo governo. Dentro desse contexto surgiu o Portal Brasileiro de Dados Abertos, para centralizar a busca e o acesso aos dados governamentais.

O Brasil é o $21^{\circ}$ colocado, em um ranking composto por 86 países, dentre os mais avançados em relação aos dados abertos governamentais, mesmo sendo membro co-fundador da Parceria para Governo Aberto. E, somente em 2016, por meio do Decreto n. 8.777/2016, institui a Política de Dados Abertos do Poder Executivo Federal. Dezessete anos após a criação do e-Gov, o Portal Brasileiro de Dados Abertos, premiado no $3^{\circ}$ Concurso de Boas Práticas da Controladoria-Geral da União, em 2015, possui pouco menos de 3.000 conjuntos de dados.

O presente trabalho tem por objetivo analisar o nível de implementação da Política de Dados Abertos (PDA) no âmbito do Poder Executivo Federal, tendo como base o Decreto n. 8.777/2016, o Manual para elaboração de PDA, do Ministério do Planejamento, Orçamento e Gestão, a Cartilha Técnica para Publicação de Dados Abertos no Brasil e o Plano de Ação da Infraestrutura Nacional de Dados Abertos. Como amostra, foram escolhidos os Ministérios e órgãos administrativos que possuem status de Ministério, totalizando 28 órgãos.

Com a análise dos dados foi constatado que dos 28 (vintee oito) órgãos analisados, somente 12 (doze) possuem o Plano de Dados Abertos disponível. Esse dado demonstra como os órgãos estão atrasados no cumprimento do Art. $9^{\circ}$, do Decreto 8.777 de maio de 2016, que dispõe que órgãos e entidades da administração pública federal direta, autárquica e fundacional, deverão elaborar e publicar seu Plano de Dados Abertos no prazo de sessenta dias após a publicação do Decreto, bem como estão em desacordo no que se refere à padronização conforme o estabelecido pelo Manual para elaboração de PDA, do Ministério do Planejamento, Orçamento e Gestão, pois apenas 7 (sete) órgãos, dos que possuem o plano, estão conforme o padrão do manual.

Tal dado é preocupante, pois o PDA é o documento orientador para as ações de implementação e promoção de abertura de dados e o manual foi elaborado para apoiar os órgãos da Administração Pública 
Federal (APF) no planejamento das ações de publicação e para normalizar as iniciativas de publicação de dados abertos do governo brasileiro. Portanto, é necessário que para que se consiga implementar a Política de Dados Abertos com dados de interesse público recuperáveis, acessíveis, de fácil compreensão e reutilizáveis, todos os órgãos sigam as diretrizes de padronização estabelecidas nos documentos como: no PDA, na Cartilha Técnica para Publicação de Dados Abertos no Brasil e no Plano de Ação da Infraestrutura Nacional de Dados Abertos que também serão objeto de análise deste trabalho.

Cabe salientar, que mesmo 16 (dezesseis) órgãos não tendo publicado o seu Plano de Dados Abertos, 21 (vinte e um) já disponibilizaram os dados no Portal Brasileiro de Dados Abertos. Nesse cenário podese depreender duas questões: a primeira, que há órgãos que ainda não têm seus dados amplamente divulgados, em formato aberto. E, a segunda, há órgãos divulgando os seus dados sem terem um plano de ação; diretrizes claras do seu cenário institucional; objetivos da divulgação dos dados; definição dos dados que serão disponibilizados em acesso aberto; ausência de descrição do processo de catalogação dos dados divulgados; falta de definição quanto ao monitoramento, controle e melhoria dos dados, dentre outros aspectos que são definidos para implementação do PDA.

Em virtude dos aspectos observados, é imprescindível que os órgãos estruturem os documentos norteadores para implementação dos dados abertos no Portal Brasileiro de Dados Abertos, bem como divulguem os dados sob forma de dados abertos, a fim de fornecer o compartilhamento e disseminação de informações visando a minimização da duplicidade de ações e do desperdício de recursos, o desenvolvimento e fomento de pesquisas científicas e de novas tecnologias, o intercâmbio de dados entre órgãos por meio de uma transparência pública e um diálogo mais facilitado entre órgãos e cidadãos.

Diante do exposto, o presente trabalho expõe o panorama dos PDA existentes dos órgãos componentes do Poder Executivo do Governo Federal e os contrapõem com a literatura e a legislação correlatas à temática.

\section{Referências}

1. Brasil. Decreto n. 8.777, de 11 de maio de 2016. Institui a Política de Dados Abertos do Poder Executivo Federal. Disponível em: http://www.planalto.gov.br/ccivil 03/ ato2015-2018/2016/decreto/D8777.htm.

2. Tribunal de Contas da União. 5 motivos para a abertura de dados na administração pública. Brasília: TCU; 2015. Disponível em: http://portal.tcu.gov.br/biblioteca-digital/cinco-motivos-para-a-abertura-dedados-na-administracao-publica.htm.

3. Laboratório Brasileiro de Cultura Digital; Núcleo de Informação e Coordenação do Ponto BR. Manual dos dados abertos: governo: traduzido e adaptado de opendatamanual.org. [São Paulo]: W3C; [2010?]. Disponível em: http://www.w3c.br/pub/Materiais/PublicacoesW3C/Manual_Dados Abertos WEB.pdf.

4. Rover AJ, Santos PM, Ferreira MVAS, Bernardes MB, Pinto CAS, Yamaoka EJ, et al. Avaliação de portais e sítios governamentais no Brasil. In: Rover AJ (Org.), Galindo F. (Org.). O Governo Eletrônico e suas múltiplas facetas. Zaragoza: Lefis Series, 2010. v. 10. p. 11-38. 